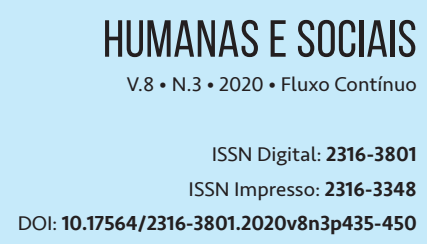

DOI: $10.17564 / 2316-3801.2020 v 8 n 3 p 435-450$

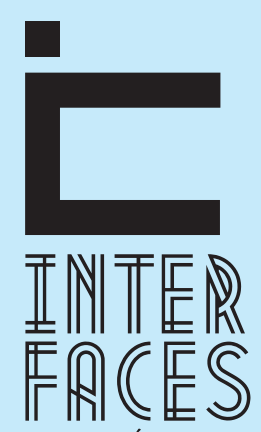

CIENTÍFICAS

\section{A TÉCNICA DA “CONSTELAÇÃO FAMILIAR SISTÊMICA" VIABILIZANDO O ACESSO A JUSTIÇA COEXISTENCIAL}

\section{"SYSTEMIC FAMLYY CONSTELLATION" TECHNIQUE ENABLING ACCESS TO COEXISTENTIAL JUSTICE}

TÉCNICA DE "CONSTELACIÓN FAMILIAR SISTÉMICA" QUE PERMITE EL ACCESO A LA JUSTICIA COEXISTENCIAL
Jéffson Menezes de Sousa ${ }^{1}$ Luane Anise Farias Santos ${ }^{2}$ Marília Mendonça Morais Sant'Anna ${ }^{3}$

\section{RESUMO}

0 presente artigo faz referência à aplicação da técnica da constelação familiar na esfera jurídica pátria como um método sistemático de solução consensual de litígios, tendo como respaldo o que dispõe o artigo $3^{\circ}, \S 3^{\circ}$ do Código de Processo Civil (CPC), que elenca possibilidades de implantação de técnicas que viabilizem a resolução de crises jurídicas. A referida técnica ultrapassa os limites da lide processual e fomenta uma justiça coexistencial cada vez mais democrática, humana, que se empenha na pacificação dos conflitos e busca soluções benéficas para as partes. Para tal abordagem, se utilizou como técnica de pesquisa a revisão bibliográfica, por meio da consulta à literatura especializada, identificando conceitos e posicionamentos pertinentes ao tema. Para fins de alcançar um judiciário verdadeiramente humanizado, é fundamental o empenho pela resolução pacífica de conflitos, em todos os âmbitos do direito, observando os interesses dos indivíduos que integram o litígio processual. Portanto, a técnica da constelação familiar está dentre os métodos de solução alternativa de conflitos, com fundamento no dispositivo processual civil, sendo um auxílio para os procedimentos autocompositivos da conciliação e mediação, contribuindo para a humanização do Poder Judiciário, onde os operadores do direito não se restrinjam apenas ao viés processualista da lide, mas que busquem a resolução de litígios de forma equilibrada, harmoniosa, preservando o relacionamento entre os envolvidos na demanda processual.

\section{PALAVRAS-CHAVE}

Constelação Familiar. Humanização Judiciária. Justiça Coexistencial. Solução de Litígios. 


\section{ABSTRACT}

This article refers to the application of the family constellation technique in the homeland legal sphere as a systematic method of consensual settlement of disputes, supported by the provisions of article 3 , paragraph 3 of the Civil Procedure Code (CPC), which lists possibilities implementation of techniques that enable the resolution of legal crises. This technique goes beyond the boundaries of procedural action, and fosters an increasingly democratic, humane coexistential justice that strives to pacify conflicts and seek beneficial solutions for the parties. For such approach, the bibliographic review was used as a research technique, by consulting the specialized literature, identifying concepts and positions pertinent to the theme. In order to achieve a truly humanized judiciary, the commitment to peaceful resolution of conflicts in all areas of law is fundamental, observing the interests of the individuals who are part of the procedural dispute. Therefore, the family constellation technique is among the methods of alternative conflict resolution, based on the civil procedural device, being an aid to the self-composing procedures of conciliation and mediation, contributing to the humanization of the judiciary, where the legal operators do not restrict themselves only to the proceduralist bias of the dispute, but seek to resolve disputes in a balanced, harmonious manner, preserving the relationship between those involved in the procedural demand.

\section{KEYWORDS}

Family Constellation. Judicial Humanization. Coexistential Justice. Dispute Resolution.

\section{RESUMEN}

Este artículo se refiere a la aplicación de la técnica de constelación familiar en la esfera legal de la patria como un método sistemático de solución consensuada de disputas, respaldado por las disposiciones del artículo 3, párrafo 3 del Código de Procedimiento Civil (CPC), que enumera las posibilidades implementación de técnicas que permitan la resolución de crisis legales. Esta técnica va más allá de los límites de la acción procesal y fomenta una justicia coexistencial cada vez más democrática y humana que se esfuerza por pacificar los conflictos y buscar soluciones beneficiosas para las partes. Para tal enfoque, la revisión bibliográfica se utilizó como técnica de investigación, consultando la literatura especializada, identificando conceptos y posiciones pertinentes al tema. Para lograr un poder judicial verdaderamente humanizado, el compromiso con la resolución pacífica de conflictos en todas las áreas del derecho es fundamental, observando los intereses de las personas que forman parte de la disputa procesal. Por lo tanto, la técnica de constelación familiar se encuentra entre los métodos de resolución alternativa de conflictos, basados en el dispositivo procesal civil, que es una 
ayuda para los procedimientos de conciliación y mediación de composición propia, contribuyendo a la humanización del poder judicial, donde los operadores legales no se limitan solo al sesgo procesalista de la disputa, pero buscan resolver las disputas de manera equilibrada y armoniosa, preservando la relación entre los involucrados en la demanda procesal.

\section{PALABRAS CLAVE}

Constelación familiar. Humanización judicial. Justicia coexistencial. Resolución de disputas.

\section{INTRODUCÇÃO}

Os meios consensuais de solução de conflitos estão se expandindo no direito brasileiro, disposto no artigo $3^{\circ}, \S 3^{\circ}$ do Código de Processo Civil (CPC) de 2015, o qual elenca possibilidades de implantação de técnicas que viabilizem a resolução de crises jurídicas. Nesse viés, surge a aplicação da técnica da constelação familiar na esfera jurídica pátria, um método sistemático de solução consensual de litígios que ultrapassa os limites da lide processual, fomentando uma justiça coexistencial cada vez mais democrática, humana, que se empenha na pacificação dos conflitos e busca soluções benéficas para as partes.

Desse modo, o presente trabalho, desenvolvido por meio de revisão bibliográfica, tem por objetivo demonstrar como a utilização da dinâmica da constelação familiar pode se mostrar como instrumento essencial de solução da crise jurídica. Nesse contexto, questiona-se: a técnica da constelação familiar sistêmica encontra respaldo no sistema multiportas disposto no artigo $3^{\circ}$, § $3^{\circ}$ do CPC como um meio alternativo de solução de conflitos?

Como forma de responder a tal indagação, a primeira seção do desenvolvimento deste artigo traz a conceituação da técnica da constelação familiar sistêmica e aborda a utilização desta como ferramenta auxiliar na solução de litígios. Posteriormente, na segunda seção, são expostos os riscos e benefícios da aplicação da técnica no Poder Judiciário, abordando como sua utilização poderá auxiliar na humanização das relações, demonstrando, ainda, o papel do jurista no desenvolvimento desse método. Por fim, na terceira seção, detalha-se como a técnica da constelação familiar sistêmica pode proporcionar o acesso à justiça coexistencial, preservando a autonomia da vontade das partes.

A técnica da constelação familiar, por meio de seus aspectos sistêmicos, encontra respaldo no sistema multiportas ${ }^{4}$ elencado no Código de Processo Civil CPC/2015, não como um método que irá substituir os meios alternativos já existentes, mas como uma ferramenta auxiliar para a conciliação e mediação, buscando a solução de enfrentamentos judiciais, facilitando a compreensão das partes

4 Refere-se à variedade de opções que cada indivíduo tem à sua disposição para procurar resolver seus conflitos por meio de diferentes métodos, um sistema que envolve procedimentos heterocompositivos e autocompositivos, que pode ou não ser estruturado pelo Estado, não sendo exigida a participação estatal (TARTUCE, 2016). 
para o problema que está em discussão, colaborando para o acesso a uma justiça coexistencial, desenvolvendo uma cultura de paz em uma sociedade que deve ser cada vez mais compassiva.

\section{A CONSTELAÇ̃̃O FAMILIAR SISTÊMICA COMO FERRAMENTA AUXILIAR NA RESOLUÇ̃̃O DE CONFLITOS: RESPALDO NO SISTEMA MULTIPORTAS DO ART. 3 ํ, $§ 30$ DO CÓDIGO DE PROCESSO CIVIL}

\subsection{DEFINIC̣ÃO DE CONSTELAÇÃO FAMILIAR SEGUNDO BERT HELLINGER}

A técnica psicoterapêutica da constelação familiar foi desenvolvida pelo psicanalista, filósofo e teólogo alemão Bert Hellinger (2008), com uma abrangência sistêmica e filosófica que envolve pontos fundamentais sobre a vida e os relacionamentos. 0 autor da técnica, com uma imensa sensibilidade para compreensão das leis que movimentam as relações humanas, devido sua vasta experiência com métodos terapêuticos, desenvolveu a sua própria terapia familiar.

0 método possui o intuito de revelar acontecimentos e trazer resolução para embates criados no inconsciente e no consciente no âmbito familiar que estejam relacionados a gerações passadas. A constelação familiar provoca uma profunda reflexão, resultando em uma transformação no comportamento e na forma de enxergar a vida e tudo que ela exige (HELLINGER; HOVEL, 2010).

Em conformidade com o entendimento de Hellinger, a terapia familiar sistêmica transforma o indivíduo em ator de sua própria história, o que exige uma responsabilidade maior e traz inúmeros benefícios para vivência em sociedade. Uma técnica sistêmica e fenomenológica que observa o ser humano de forma não isolada, inserindo este em um sistema familiar controlado por forças e conexões ocultas.

A técnica da constelação familiar foi desenvolvida com base em 3 leis sistêmicas, as quais foram denominadas por Bert Hellinger (2007) como ordens do amor, que são: o pertencimento, a hierarquia (ou ordem), o equilíbrio (ou compensação). Uma forma de buscar compreender o indivíduo incluído em um ambiente, que pode ser familiar ou não, o qual é orientado por leis naturais, que, se não observadas, podem gerar acontecimentos desagradáveis (HELLINGER; SCHNEIDER, 2007).

Essas ordens pré-ajustadas estão presentes nos desenvolvimentos que ocorrem no âmbito familiar, quando são aplicadas, fazem com que seja cessada toda responsabilidade por injustiças que foram praticadas na família. Por isso:

Nas constelações familiares as "ordens do amor" desempenham um papel importante, principalmente no que diz respeito ao sucesso dos relacionamentos. Naturalmente essas ordens se encaixam nos processos complexos e mutáveis das relações. Justamente por isso a compreensão de como atuam essas ordens é tão útil para orientar essas relações em suas dificuldades. (HELLINGER; SCHNEIDER, 2007, p. 51). 
Nas constelações familiares é utilizada uma abordagem fenomenológica, em que é revelada uma compreensão maior de fenômenos, que só se manifestam e podem ser solucionados quando e observados sem julgamentos.

Não existe uma explicação concreta para os sintomas que são sentidos pelos representantes no momento da constelação, são sensações alheias. O importante é a busca pela solução do conflito que é exposto, fazendo com que o indivíduo encontre o equilíbrio e a paz que procura, reencontrando o respeito e carinho daqueles que foram retirados e são reintegrados no sistema familiar (HELLINGER; WEBER; BEAUMONT, 2008).

Portanto, com base nas leis sistêmicas que orientam a técnica das constelações familiares, será possível proporcionar ao constelado, por meio do auxílio de um constelador sistêmico, a compreensão de problemas, por meio da visualização e reconhecimento de seus vínculos e origens, fazendo com que esse indivíduo enxergue as situações conflituosas e almeje a solução para o conflito. Em razão desse fato, no próximo item será analisado como esse método pode ser crucial na solução de conflitos e como ele pode contribuir para a humanização do Poder Judiciário brasileiro.

\subsection{A BUSCA PELA ADEQUADA PRESTAÇÃo JURISDICIONAL E A DESCARACTERIZAÇ̃̃o DA CULTURA DO LITíGIO}

O direito brasileiro, por muito tempo, orientou-se pelo paradigma do litígio e pela valorização do conflito, mas, com o passar dos anos, a cultura jurídica da pacificação de controvérsias foi ganhando espaço, sendo deflagrada uma maior abrangência dos procedimentos autocompositivos, expandindo a busca pela solução consensual do litígio.

Embora o conflito seja tratado, na maioria das vezes, como algo negativo e repudiante, este pode ser necessário em alguns casos, uma vez que permite a expressão e indagação de inúmeras opiniões. A negativação imposta não está necessariamente no conflito, mas na forma como ele é analisado e como são produzidas as opiniões contrárias que podem criar agitações nas relações humanas (LIPPMANN; OLDONI, 2018).

Com base na garantia constitucional de acesso à justiça, elencado na Constituição Federal (CF) de 1988 em seu art. $5^{\circ}$, XXXV, é garantida ao cidadão a resolução de seus conflitos por meio do Poder Judiciário, o que resultou em uma demanda intensa de acesso jurisdicional, gerando uma superlotação, o que resulta em uma espera maior para solução das demandas e consequente ineficácia processual para as partes (LIPPMANN; OLDONI, 2018).

Assim sendo, houve a necessidade de introduzir no Poder Judiciário um sistema hábil a oferecer mecanismos de solução de litígios de forma consensual, onde é concedido às partes o espaço necessário para que resolvam os seus conflitos, que sejam protagonistas nessa resolução, que entendam o porquê de terem ingressado com aquela demanda, sendo necessário compreender a controvérsia para saber lidar com ela.

A autocomposição exige das partes litigantes um amadurecimento emocional e racional, uma vez que quebra o paradigma do discurso defensivo e retira a competência de solução da lide por terceiros, devolvendo aos conflitantes a obrigação de compreender e resolver as desavenças que resultaram na ação (CÉSPEDES, 2017). 
A estrutura do Poder Judiciário é triangular, onde o Estado-Juiz, por meio de um terceiro imparcial, profere uma decisão judicial como forma de resolver a lide em debate, tomando como base os limites estabelecidos na lei, sendo desconsiderados fatores intrínsecos à demanda discutida. Por isso, para que o conflito seja resolvido de forma eficaz e equilibrada, não se pode impor ao Estado-Juiz a unilateralidade em resolver as demandas processuais (LIPPMANN; OLDONI, 2018).

Dessa forma, para que ocorra uma adequada prestação jurisdicional e que seja descaracterizada toda cultura de litígio é necessário que as partes busquem a autocomposição, dando espaço para a solução de conflitos de forma consensual, sem disputa. Nesse viés, no próximo item será exposto como a técnica da constelação familiar sistêmica pode se transformar em auxílio para os métodos de resolução alternativa de conflitos já existentes.

\subsection{A TÉCNICA DA CONSTELAÇÃO FAMILIAR SISTÊMICA FACILITANDO A CONCILIAÇ̃̃o E MEDIAÇÃO DE CONTROVÉBSIAS}

Como forma de garantir a eficácia na prestação jurisdicional, foi implementado um "sistema multiportas" no judiciário, disposto a ofertar meios alternativos de resolução de conflitos, direcionado à edificação do consenso e da harmonia entre as partes, desconsiderando o antigo modelo dividido entre ganhar ou perder.

Por esse motivo, o Conselho Nacional de Justiça (CNJ), por meio da Resolução n 125/2010 (CNJ, 2010), promoveu uma política de estímulo à solução dos conflitos por meio de meios alternativos, objetivando a organização do ambiente jurídico brasileiro para as futuras legislações sobre o tema. Em momento posterior, ocorreu a edição da Lei no 13.140/2015 (Lei de Medição) e a atualização do CPC (Lei n 13.105/2015), proporcionando a ampliação do sistema multiportas.

A utilização de meios consensuais de solução de conflitos está se expandindo no direito brasileiro, com respaldo no artigo $3^{\circ}, \S 3^{\circ}$ do CPC, o qual elenca possibilidades de implantação de técnicas que viabilizem a resolução de crises jurídicas. Métodos que estão sendo expandidos no Poder Judiciário e que devem ser fomentados por juízes, defensores públicos, advogados, membros do Ministério Público, devendo ser utilizados em todo o trâmite processual.

Os principais métodos de solução pacífica de conflitos elencados no CPC foram a conciliação e mediação, sendo estas técnicas consideradas como impulso para a resolução demandas processuais de forma pacífica e cooperativa, onde é permitido às partes resolverem seus problemas de forma mais célere e sem tanto desgaste físico e emocional.

Os métodos que foram apresentados são essenciais para o Poder Judiciário, possuindo cada um as suas particularidades, sendo que ambos objetivam tanto a solução do conflito existente entre os envolvidos, como também a proteção do equilíbrio na relação entre as partes.

É nesse contexto que surgem outros meios alternativos que buscam também a solução de crises jurídicas e intentam a obtenção de resultados positivos nas ações que estão sendo discutidas no Poder Judiciário, dentre essas técnicas, está em destaque à constelação familiar, considerada um procedimento que pretende obter soluções definitivas e satisfatórias para as demandas processuais.

Por meio da constelação familiar é possível que seja revelado o que está internalizado nas partes, o que não se pode ver ou perceber. Diante disso, torna-se possível a sensibilização dos envolvidos no conflito, possibilitando, ao final, uma decisão satisfatória e justa (LIPPMANN; OLDONI, 2018). 
Pelo exposto, constata-se que a constelação familiar, por meio de seus aspectos sistêmicos, encontra respaldo no sistema multiportas disposto no art. $3^{\circ}, \S 3^{\circ}$ do $C P C$, não como uma técnica que irá substituir os meios alternativos já existentes, mas como uma ferramenta auxiliar para a conciliação e mediação, buscando a solução de enfrentamentos judiciais, facilitando a compreensão das partes para o problema que está em discussão. A seguir serão elencados os possíveis riscos e benefícios da aplicação da técnica da constelação familiar no Poder Judiciário, sendo importante destacar como esse método pode humanizar as relações sociais e como os juristas podem contribuir para a disseminação da autocomposição.

\section{RISCOS E BENEFÍ́CIOS DA APLICAÇÃO DA CONSTELAÇÃO FAMILIAR SISTÊMICA NO PODER JUDICIÁRIO}

\subsection{HUMANIZAÇ̃̃O DAS RELAÇ̃̃ES SOCIAIS POR MEIO DA AUTOCOMPOSIÇÃO}

A técnica da constelação familiar sistêmica quando aplicada, porque, além de contribuir com a redução de demandas no judiciário e impedir que novos conflitos sejam gerados, visa à preservação dos vínculos afetivos entre os envolvidos no litígio, pois ela faz com que o problema seja compreendido do início, o que proporciona a solução definitiva da lide, onde as partes se satisfazem com a decisão final.

É preciso que o indivíduo tenha um olhar mais humano para a pessoa que está do outro lado da lide, não enxergando como um adversário, mas como alguém que possui princípios, opiniões diferentes. Se estas pessoas se desligarem do sentimento do conflito, chegarão a uma decisão justa, satisfatória, fazendo com que, ao final, não existam perdedores ou ganhadores, mas partes que resolveram de forma harmônica as suas desavenças.

Com a técnica da constelação familiar como método alternativo de solução de controvérsias são abertas novas portas para que o direito evolua diante dos novos parâmetros do conflito e dos constantes anseios da população pela solução eficaz dos processos judiciais.

Antes de buscar solucionar o problema debatido, é necessário que os envolvidos no litígio busquem compreender um ao outro, sem julgamento, egoísmo, internalizando o desejo da reconciliação.

Um amparo para a autocomposição, a constelação familiar sistêmica auxilia na mudança do pensamento dos conflitantes, fazendo com que estes identifiquem seus problemas, enxerguem a situação que está sendo debatida de maneira racional, e busquem solucionar suas contendas.

Por meio da técnica da constelação familiar sistêmica torna-se possível a obtenção de novos pontos de vista acerca da realidade de cada parte que integra o conflito, sendo respeitadas as opiniões que são expostas, sem julgamento pessoal, tratando um ao outro com empatia. Seguindo esse viés, o Poder Judiciário adquire um olhar mais humanizado para os indivíduos envolvidos na lide, assumindo o compromisso de, não só julgar, mas de reestabelecer as relações (LIPPMANN; OLDONI, 2018).

Como forma de amenizar os extensos conflitos existentes no judiciário, o legislador buscou desenvolver meios para superar o antigo paradigma da disputa judicial, por isso, como já mencionado anteriormente, foram criados mecanismos para solucionar os conflitos de forma consensual, inician- 
do-se pela Resolução de n 125/2010 (CNJ, 2010), posteriormente a Lei n 13.140/2015 - Lei de Medição e mais recentemente a atualização do CPC em 2015, o qual passou por mudanças significativas em relação à inclusão de métodos alternativos de solução de conflitos.

Dessa forma, antes mesmo da reestruturação procedimental do Código de Processo Civil, já era almejada a criação de um novo cenário processual brasileiro, o qual precisava destacar a autocomposição como forma de solução de conflitos.

O convívio social pacífico e harmônico ainda é visualizado como uma utopia, como uma visão conturbada e pendente de aceitação. Grande parte da sociedade ainda não recepcionou a ideia de resolução de litígios de forma consensual, mas a autocomposição já está ganhando espaço e, aos poucos, o ideal conflitante será extinto.

Um desafio que pode ser enfrentado ao buscar a utilização da técnica em ações em trâmite no Poder Judiciário será em relação à aceitação das partes em conciliar, em chegar a um bem comum, um acordo, podendo essas pessoas não estar dispostas a reconhecer os erros que foram cometidos, ou buscar entender os motivos da parte contrária.

Ainda, é necessário ter cautela para que essa técnica não rejeite a aplicação de todo o sistema de organização desenvolvido pelo direito, o qual possibilita a manutenção da ordem no âmbito social. Por isso, é preciso buscar formas de manter a estrutura conquistada pelo Estado Democrático de Direito, mas procurando medidas que possam ampliar e auxiliar a tentativa de harmonizar e humanizar as relações sociais (LIPPMANN; OLDONI, 2018).

A técnica da constelação familiar não será utilizada como forma de substituir os meios de solução pacífica de conflitos já existentes, mas como um grande auxílio para esses métodos, servindo, até mesmo, como preparação para as partes antes de dar início a uma audiência de conciliação, mediação. Será uma forma de trazer os sentimentos ocultos das partes, despertando o espírito conciliativo, auxiliando na formulação de acordo entre os litigantes.

Embora não exista um real alcance da aplicação da técnica da constelação familiar sistêmica no cenário jurídico brasileiro, sendo algo em fase de estabilidade e aceitação por parte dos juristas, já são compartilhados relatos positivos do uso da dinâmica em diversos casos, sendo, em todos eles, demonstrada a satisfação das partes pela decisão que é construída. Ainda, cumpre ressaltar que várias comarcas brasileiras já recepcionaram a utilização da técnica, como será exposto logo a seguir.

\subsection{A ATUAC̄̃̃ DO JURISTA SOB A ÓTICA DO PENSAMENTO SISTÊMICO}

É preciso que os operadores do direito assumam o compromisso de aderir a uma nova postura voltada para o direito sistêmico, onde irão desempenhar o papel de facilitadores na ampliação da consciência das partes, na compreensão da origem de seus conflitos, fazendo com que seja obtida uma solução rápida e eficaz do litígio, trazendo satisfação para todos os envolvidos.

Logo, é imprescindível que todos os juristas possuam um viés amplo e livre de posicionamentos formados para a disputa, sendo crucial que enxerguem por meio do superficial, não visualizem somente o caso que é colocado em análise, mas que promovam uma justiça erguida pela harmonia, obedecendo à hierarquia, ao equilíbrio, à ordem. 
A técnica da constelação familiar sistêmica já vem sendo utilizada pelo Poder Judiciário, sendo que o precursor da aplicação de tal dinâmica é o juiz Sami Storch, da $2^{\mathrm{a}}$ Vara de Família de Itabuna/ BA, que desde 2006 vem utilizando as constelações familiares para resolver litígios judiciais em sua comarca (LIPPMANN; OLDONI, 2018).

O juiz Sami Storch (2015) buscou aperfeiçoar seus conhecimentos acerca das constelações familiares, e, após um primeiro contato com a técnica, viu que esta seria muito válida se aplicada como auxílio para resolução de conflitos em desenvolvimento no ordenamento jurídico.

O desenvolvimento da ciência sistêmica é uma forma de ampliar a compreensão das dinâmicas que estão escondidas nos litígios, por isso cada indivíduo que faz parte do conflito possui motivos para estar presente nele e essas circunstancias possuem raízes profundas, que não estão relacionadas especificamente com a parte que integra o processo, mas sim com o histórico familiar de cada um, de gerações passadas (STORCH, 2017).

Com a dinâmica da constelação familiar sistêmica torna-se possível transparecer o que está oculto, trazendo à tona o que não se pode perceber, por meio da sensibilização das partes que integram o conflito, fazendo com que seja alcançada, na maioria dos casos, uma decisão justa e sincera para as partes (OLDONI; LIPPMANN; GIRARDI, 2018).

É crucial que o Magistrado esteja liberto de julgamentos, que busque, primeiramente, conhecer a situação de todas as partes ali presentes, como forma de proporcionar uma busca pela conciliação entre os envolvidos, fazendo com que estes aceitem a decisão que será construída, pois as partes irão sentir que foram notadas pelo juiz e que o problema que foi exposto pode ser resolvido de forma satisfatória:

Cabe ao magistrado, antes de sentenciar, considerar essa realidade e ter um olhar terno e isento de julgamentos pessoais em relação a todos que compõem esse sistema em desequilíbrio. Esta postura do juiz já estará contribuindo para o equilíbrio do sistema e no caso da necessidade de uma decisão impositiva ser tomada, será ele mais bem recebida pelos envolvidos, pois todos sentirão que foram vistos e considerados pelo juiz. Esta aproximação entre o Direito e as constelações é feita com ambos os litigantes de um processo ou com apenas uma das partes, onde a constelação familiar para verificar a verdadeira razão de seu comportamento ou da parte adversa e qual a melhor solução para o caso, ou seja, em que momento e qual destas leis descritas acima foram quebradas, gerando um desequilíbrio de difícil solução para todo o sistema. (OLDONI; LIPPMANN; GIRARDI, 2018, p. 59).

O magistrado Sami Storch aplica a dinâmica das constelações por meio da utilização de frases sistêmicas, como forma de sensibilizar as partes envolvidas no litígio, por meio do projeto para realização de uma palestra vivencial, com a presença de pessoas que estão envolvidas nas demandas judiciárias na área de família (STORCH, 2015).

Não existem dados estatísticos nacionais concretos de que a técnica da constelação familiar está sendo aplicada no âmbito jurídico e está sendo eficaz na solução de conflitos, mas projetos desenvolvidos com base nessa dinâmica já estão sendo implantados em inúmeros tribunais brasileiros (FARIELLO, 2018). 
A técnica da constelação familiar já está obtendo resultados positivos em tribunais de 16 Estados, são eles: Goiás, Ceará, São Paulo, Rondônia, Bahia, Mato Grosso, Mato Grosso do Sul, Santa Catarina, Alagoas, Sergipe, Amapá, Distrito Federal e, segundo levantamento realizado pelo CNJ (2018), fomentando decisões mais justas, garantindo um acesso efetivo à justiça. Ademais, também tramita na câmara dos deputados o Projeto de Lei n 9.444, de 2017, que busca a inclusão da constelação sistêmica como um instrumento de mediação entre particulares, a fim de assistir à solução de controvérsias.

Ainda, recentemente vem sendo implantado no ordenamento jurídico a advocacia sistêmica, uma nova maneira de os profissionais do direito buscarem se relacionar com seus clientes de forma estratégica consensual, adotando uma postura humanizada, adquirindo um perfil pacificador, visando o conflito como algo positivo e transformador, evitando a judicialização das demandas e desenvolvendo melhores acordos (OLDONI; LIPPMANN; GIRARDI, 2018).

Por muito tempo foi disseminada a ideia de que, para exercer a advocacia de forma correta, seria necessário saber litigar, mas, aos poucos, essa visão está sendo distorcida e novos paradigmas jurídicos estão sendo desenvolvidos por meio do pensamento sistêmico, o qual proporciona a solução dos litígios pela comunicação eficaz entre as partes.

$\mathrm{O}$ advogado, guiado pelas ordens do amor desenvolvidas por Bert Hellinger, relaciona-se com seus clientes por meio da utilização de técnicas sistêmicas de comunicação que não transmitam violência, colocando como base do relacionamento o equilíbrio, a busca pela solução consensual do conflito, transformando a cultura do litígio em uma cultura de paz (OLDONI; LIPPMANN; GIRARDI, 2018).

O método das constelações familiares sistêmicas ainda está em fase de introdução no âmbito do Poder Judiciário, mas, de acordo com os projetos que foram apresentados acima, diante dos resultados positivos que estão sendo obtidos pelo juiz Sami Storch e por meio da construção de uma advocacia sistêmica, torna-se totalmente viável a aplicação da dinâmica sistêmica, já abarcada pelo sistema multiportas do judiciário brasileiro, para obtenção de uma cultura de paz voltada para a solução de controvérsias.

\section{ACESSO À JUSTIÇA COEXISTENCIAL E A AUTONOMIA DA VONTADE DAS PARTES}

O direito fundamental de acesso à justiça possui grande importância na preservação e promoção da dignidade da pessoa humana e visa assegurar aos cidadãos a possibilidade de buscar o Poder Judiciário de forma livre e abrangente, para solução de suas contendas, garantindo a tutela dos seus direitos (SILVA, 2017).

Independentemente da via pela qual será proporcionado o acesso à justiça, seja por meio consensual ou judicial, o importante é disponibilizar às partes inúmeras possibilidades de solução para o conflito, pois quanto mais opções forem visualizadas, maior será a probabilidade de obter um resultado satisfatório.

0 acesso à justiça precisa ser visto como um requisito fundamental para criação de um sistema jurídico moderno e que transmita igualdade, que vise garantir, e não apenas anunciar direitos aos indivíduos (CAPPELETTI; GARTH, 1988). 
É necessário superar alguns óbices para que o direito de acesso à justiça seja efetivamente ampliado, dentre esses obstáculos pode-se destacar os de natureza econômica, social, cultural e legal. Para melhor compreensão do tema exposto, vale explicar individualmente o sentido de cada empecilho.

Dentre as mais recorrentes restrições ao acesso à justiça podem ser identificadas as que estão relacionadas à condição econômica das partes. A necessidade de arcar com custas processuais, honorários advocatícios e periciais podem ser caracterizados como fator que inibe o acesso à justiça de grande parte dos indivíduos com hipossuficiência financeira (CAPPELETTI; GARTH, 1988).

Ainda, diante da morosidade das demandas processuais, é gerado um alto custo econômico para as partes e para as que possuem carência econômica a busca pela concretização de seus direitos por meio do Poder Judiciário fica ainda mais árdua.

Outro fator que gera dificuldade em buscar meios para resolução de litígios está ligado a circunstâncias de ordem social e cultural, uma vez que grande parte da população desconhece os direitos e deveres que the são inerentes e quanto mais baixo o extrato social, maior a impossibilidade de aproximação com o sistema da justiça (CABRAL, 2012).

Por esse motivo, fatores como a utilização de uma linguagem rebuscada e com termos técnicos, os procedimentos formais, a distinção entre posições sociais, criam ainda mais empecilhos e desestimulam a procura pela solução de controvérsias no sistema jurídico.

Paira no judiciário brasileiro uma indesejada morosidade, que causa um desestímulo em grande parte dos cidadãos, o que leva as pessoas a deixarem de expor as suas pretensões, tendo em vista a impossibilidade de esperar um longo período pela decisão final a ser proferida pelo julgador, que, em alguns casos, não gera total satisfação às partes.

Uma demanda processual quando desenvolvida pelo padrão tradicional é envolta pela justiça do conflito, ou seja, no processo estão presentes opiniões divergentes entre as partes autora e ré, um terceiro é que possui autonomia para julgar e impor quem possui o direito pleiteado (SILVA, 2017).

Na justiça conflitual, os integrantes do processo se enfrentam e a demanda é regida por um terceiro (Juiz), o qual possui a obrigação de decidir de forma imperativa, estabelecendo, ao final, quem é vencedor ou vencido, o que gera uma perda ou ganho. Enquanto na justiça coexistencial as partes contribuem e controlam a demanda processual, decidindo tanto questões presentes como futuras, resultando em uma solução eficaz e satisfatória.

É notável que, quando as partes optam pela solução consensual, maiores benefícios são adquiridos, pois, em uma decisão impositiva, na maioria das vezes, não são observadas todas as pretensões das partes, o que ocasiona uma profunda insatisfação, gerando maiores discursões, prolongando a disputa judicial.

Quando as partes estão dispostas a dialogar sobre o conflito, não abordando apenas questões passadas, mas incluindo o futuro como cenário a ser considerado, é aplicada a lógica coexistencial, onde a autonomia dos indivíduos prevalece e o terceiro que integra o conflito deverá agir apenas como facilitador na comunicação, não intervindo na solução da lide, viabilizando o diálogo e objetivando uma decisão produtiva (TARTUCE, 2016).

A essência da justiça coexistencial é a solução dos conflitos por meio dos métodos autocompositivos, onde as partes cooperam e resolvem as suas demandas de forma pacífica, por meio do diálogo e da discussão produtiva, chegando a um consenso, uma solução que agrada a todos. 
Antes das modificações que foram realizadas no CPC de 2015, a Constituição Federal de 1988 já previa a ampliação do acesso à justiça, onde foi estipulado que o Poder Judiciário deverá prestar atendimento amplo aos cidadãos e abranger o máximo de reclamações, ou seja, os juristas devem multiplicar as portas de acesso ao judiciário, como forma de proteger os direitos (SILVA, 2017).

Essa justiça multiportas refere-se à variedade de opções que cada indivíduo tem à sua disposição para procurar resolver seus conflitos por meio de diferentes métodos, um sistema que envolve procedimentos heterocompositivos e autocompositivos, que pode ou não ser estruturado pelo Estado, não sendo exigida a participação estatal (TARTUCE, 2016).

Os sujeitos integrantes do conflito possuem autonomia em escolher a forma como a demanda será solucionada, as partes são independentes para buscar os meios suficientes para chegar a um acordo ou também podem divergir e não aceitar a tentativa consensual, o que deve prevalecer é vontade dos litigantes, estes dominam o poder de escolha.

A partir do momento em que uma pessoa acessa o judiciário, deverá ser apresentado um leque de possibilidades para solução da lide, devendo ser expostas todas as oportunidades, tanto pela sentença prolatada pelo juiz, quanto pelos métodos alternativos de resolução de conflitos, como a conciliação, a mediação, a técnica das constelações familiares sistêmicas, sempre mostrando as vantagens que possui uma composição (SILVA, 2017).

Vale ressaltar que a solução judicial para os litígios não é a única opção existente, sendo que esta via nem sempre é a mais adequada, devendo ser considerado que, no âmbito do Poder Judiciário, os sentimentos sempre são mais divergentes e as contradições entre as opiniões expostas geram um desgaste causado pelo caráter litigioso entre ganhar ou perder.

O objetivo deve ser sempre oferecer às partes diversas possibilidades para solucionar a lide, seja por meio de métodos consensuais ou por meio da via judicial, uma vez que, quanto mais opções estiverem à disposição, maior será a chance das partes chegarem a um resultado harmônico e eficaz (SILVA, 2017).

Pelo exposto, para que seja garantido um efetivo acesso à justiça coexistencial, é necessário disponibilizar as partes amplas possibilidades de resolução de conflitos, dando-se preferência aos meios consensuais, onde os sujeitos da demanda possuem autonomia para buscar a solução de sua lide da forma mais vantajosa e equânime.

\section{CONCLUSÃO}

Regida por leis sistêmicas, utilizando uma abordagem fenomenológica, a técnica da constelação familiar revela-se como forma de compreensão de fenômenos, que só se manifestam e podem ser solucionados quando observados sem julgamentos. Por meio da utilização da técnica como forma se resolução consensual de conflitos, será possível introduzir no Poder Judiciário um sistema hábil de autocomposição, concedendo às partes o espaço necessário para que estas resolvam as suas contendas de forma amigável.

Diante da descaracterização do conflito e com a valorização da cultura jurídica da pacificação de controvérsias, foi possível uma maior abrangência dos procedimentos autocompositivos, expandindo 
a busca pela solução consensual de litígios. 0 método da constelação familiar sistêmica pode se mostrar como um grande auxílio para os procedimentos da conciliação e da mediação, fazendo com que sejam resolvidas as contendas judiciais de forma harmônica e sem disputa.

Na sessão de constelação familiar é proporcionada às partes, pelo auxílio do constelador sistêmico, a compreensão de seus problemas, por meio da visualização e reconhecimento de seus vínculos e origens, fazendo com que os indivíduos enxerguem as situações conflituosas e almejem a solução para a contenda.

Ainda não existe um real alcance da aplicação da técnica das constelações familiares sistêmicas no cenário jurídico brasileiro, sendo um método em fase de estabilidade e aceitação por parte dos juristas, mas já são compartilhados relatos positivos do uso da dinâmica em diversos casos, sendo, em todos eles, demonstrada a satisfação das partes pela decisão que é construída.

Portanto, a técnica da constelação familiar, por meio de seus aspectos sistêmicos, encontra respaldo no sistema multiportas, elencado no art. $3^{\circ}, \S^{\circ}$ do CPC, e sua aplicação contribui de forma significativa para a humanização do Poder Judiciário, por meio da solução consensual de litígios, proporcionando às partes uma maior satisfação com a decisão final, evitando novos dissensos. Ainda, essa dinâmica colabora para o acesso a uma justiça coexistencial, desenvolvendo uma cultura de paz em uma sociedade que deve ser cada vez mais compassiva.

\section{REFERÊNCIAS}

BRASIL. Conselho Nacional de Justiça. Resolução n 125, de 29 de novembro de 2010. Disponível em: http://www.cnj.jus.br/busca-atos-adm?documento=2579. Acesso em: 29 set. 2019.

BRASIL. Lei 13. 105/2015, de 16 de março de 2015. Disponível em: http://www.planalto.gov.br/ ccivil_03/_Ato2015-2018/2015/Lei/L13105.htm. Acesso em: 30 set. 2019.

BRASIL. Lei 13.140/2015, de 26 de junho de 2015. Dispõe sobre a mediação entre particulares como meio de solução de controvérsias e sobre a autocomposição de conflitos no âmbito da administração pública; altera a Lei n ${ }^{\circ}$ 9.469, de 10 de julho de 1997, e o Decreto $n^{\circ} 70.235$, de 6 de março de 1972; e revoga o $\S 2^{\circ}$ do art. $6^{\circ}$ da Lei ${ }^{\circ} 9.469$, de 10 de julho de 1997. Disponível em: http://www.planalto.gov. br/ccivil_03/_ato2015-2018/2015/Lei/L13140.htm. Acesso em: 29 set. 2019.

BRASIL. Constituição da República Federativa do Brasil, 1988. Brasília, DF: Senado Federal; Centro Gráfico, 1988.

CABRAL, Marcelo Malizia. Os meios alternativos de resolução de conflitos: instrumentos de ampliação do acesso à justiça. Dissertação (Mestrado Profissional em Poder Judiciário) - FGV Direito Rio, Rio de Janeiro, 2012. Disponível em: http://hdl.handle.net/10438/18756. Acesso em: 29 out. 2019. 
CAPPELETTI, Mauro; GARTH, Bryant. Acesso à justiça. Tradução de Ellen Gracie Northfleet. Porto Alegre: Sergio Antonio Fabris Editor, 1988. Disponivel em: https://www.irib.org.br/app/webroot/ publicacoes/diversos003/pdf.PDF. Acesso em: 29 out. 2019.

CARDOSO, Hélio Apoliano. Direito de família à luz da constelação familiar e do direito sistêmico. Revista Síntese de Direito de Família, São Paulo, v. 17, n. 97, p. 75-78, ago./set. 2016. Disponível em: http://www.mpsp.mp.br/portal/page/portal/documentacao_e_divulgacao/doc_biblioteca/ bibli_servicos_pro dutos/bibli_boletim/bibli_bol_2007/Rev.Sint.Dir.Fam_n.97.pdf. Acesso em: 16 set. 2019.

CÉSPEDES, Adele Speck Rendón. A constelação familiar aplicada ao direito brasileiro a partir da lei de mediação. 2017. Monografia (Curso de Direito) - UFSC, Florianópolis, 2017. Disponível em: https://repositorio.ufsc.br/handle/123456789/177310. Acesso em: 31 ago. 2019.

DINAMARCO, Cândido Rangel. A novo era do processo civil. São Paulo: Malheiros, 2003. Disponível em: https://pt.scribd.com/document/263469057/Candido-Rangel-Dinamarco-Nova-Era-DoProcesso-Civil-2003. Acesso em: 20 set. 2019.

FARIELLO, Luiza. Constelação familiar: no firmamento da justiça em 16 estados e no DF. Portal CNJ, abril 2018. Disponível em: http://www.cnj.jus.br/noticias/cnj/86434-constelacao-familiar-nofirmamento-da-justica-em-16-estados-e-no-df. Acesso em: 17 set. 2019.

HELLINGER, Bert. Ordens do amor: um guia para o trabalho com constelações familiares, Tradução de por Newton de Araújo Queiroz. São Paulo: Cultrix, 2003. Disponível em: https://pt.scribd.com/ doc/220741124/Ordens-Do-Amor-Bert-Hellinger-30-4-2013. Acesso em: 28 ago. 2019.

HELLINGER, Bert; WEBER, Gunthard; BEAUMONT, Hunter. A simetria oculta do amor. São Paulo: Cultrix, 2008. Disponível em: https://www.galaxcms.com.br/imgs_redactor/1176/files/A-SimetriaOculta-Do-Amor-Bert-Hellinger-2012.pdf. Acesso em: 31 ago. 2019.

HELLINGER, Bert; HÖVEL, Gabriele Ten. Constelações familiares: o reconhecimento das ordens do amor. Tradução de Eloisa Giancoli Tironi e Tsuyuko Jinno-Spelter. São Paulo: Editora Cultrix: 2010. Disponível em: http://criacoessistemicas.com.br/wpcontent/uploads/2017/03/ CONSTELAC\%CC\%A70\%CC\%83ES-FAMILIARES-Bert-Hellinger.pdf. Acesso em: 31 ago. 2019.

HELLINGER, Bert; SCHNEIDER, Jakob Robert. A prática das constelações familiares. Tradução de Newton A. Queiroz. - Patos de Minas: Atman, 2007. Disponível em: https://constelacoesfamiliarespt. files.wordpress.com/2012/12/a-prc3a1tica-das-constelac3a7c3b5es-familiares-jakob-schneider. pdf. Acesso em: 31 ago. 2019. 
LIPPMANN, Márcia Sarubbi; OLDONI, Fabiano. Um novo olhar para o conflito: diálogo entre mediação e constelação sistêmica. Joinville, SC: Manuscritos, 2018.

LIPPMANN, Márcia Sarubbi; OLDONI, Fabiano e GIRARDI, Maria Fernanda Gugelmin. Direito sistêmico: aplicação das leis sistêmicas de bert hellinger ao direito de família e ao direito penal. Joinville, SC: Manuscritos, 2018.

SILVA, Manoella Cabral Dias da. A justiça coexistencial e a nova sistemática da audiência de conciliação e sessão de mediação no código de processo civil de 2015. Trabalho de Conclusão de Curso (Curso de especialização em Processo Civil) - Faculdade de Direito, Universidade Federal do Rio Grande do Sul, Porto Alegre, RS, 2017. Disponível em: https://lume.ufrgs.br/ handle/10183/184619. Acesso em: 28 out. 2019.

STORCH, Sami. Direito sistêmico: primeiras experiências com constelações no judiciário, 2015. Disponível em: https://direitosistemico.wordpress.com/2016/08/23/publicado-artigo-sobre-asprimeiras-experiencias-com-constelacoes-no-judiciario/. Acesso em: 31 ago. 2019.

TARTUCE, Fernanda. Mediação nos conflitos civis. 3. ed. rev. atual. e ampl. São Paulo: Editoria Método, 2016. 
1 Mestre em Direitos Humanos pela Universidade Tiradentes - UNIT/SE; Doutorando em Direito pelo Centro Universitário de Brasília - UniCEUB/DF com bolsa pelo PROSUP/ Capes; Professor Adjunto do curso de Direito da UNIT/SE. E-mail: menezes.sousaadv@gmail.com

2 Graduada em Direito pela Universidade Tiradentes UNIT/SE. E-mail: anisesantos@gmail.com

3 Doutora em Direito Político e Econômico - UPM/SP; Mestre em Direito do Estado - PUC/SP; Advogada; Professora Adjunta do curso de Direito da UNIT/SE.

E-mail: mmsantanna@hotmail.com

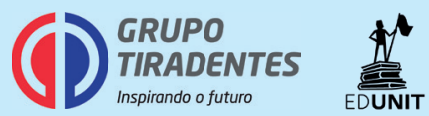

